\title{
PERSPECTIVAS DE ANÁLISE DO AMBIENTALISMO EMPRESARIAL PARA ALÉM DE DEMONIZAÇÕES E SANTIFICAÇÕES
}

\author{
Sylmara Lopes Francelino Gonçalves Dias \\ Doutora em Administração de Empresas - FGV \\ Professora da Universidade São Paulo - USP \\ sylmaraldias@gmail.com \\ Armindo dos Santos de Sousa Teodósio \\ Doutor em Administração de Empresas - FGV \\ Professor Pontifícia Universidade Católica de Minas Gerais - PUC \\ teodosio@pobox.com
}

\section{RESUMO}

$\mathrm{O}$ artigo de natureza teórico-conceitual discute as inovações com relação ao meio ambiente desenvolvidas pelas organizações. A partir do arcabouço teórico da teoria institucional, analisa-se as diferentes motivações e estratégias que podem levar as empresas a assumirem um discurso e uma postura de responsabilidade ambiental que seja legitimada pela sociedade, bem como os desafios que se apresentam diante dos diferentes quadros interpretativos sobre o fenômeno do chamado "Ambientalismo Empresarial". A partir da noção de mercados como instituições socialmente construídas, se chega a um quadro teórico-compreensivo das inovações ambientais empresariais. Nesse modelo teórico, apresentam-se quatro grandes eixos que podem ser delineados quanto à inovação ambiental desenvolvida pelas empresas, a saber, (1) Captura, (2) Construção de Ponte, (3) Criação de um Novo Campo e (4) Defesa. Os fenômenos que envolvem a dinâmica empresarial em direção a algum desses quadrantes são entendidos por meio das noções de capital social, político e econômico em operação quando atores de mercado, da sociedade civil e da esfera do Estado estão em interação. A análise aponta uma série de desafios que se apresentam frente à necessidade de se construir estratégias de inovação em gestão ambiental mais sintonizadas com os recentes avanços na discussão e nas lutas socioambientais contemporâneas. Temáticas que podem ser objeto de outras investigações e até mesmo de modelos compreensivos concorrentes ao exposto no artigo.

Palavras-chave: Ambientalismo Empresarial; Sustentabilidade; Gestão Ambiental; Responsabilidade Social Empresarial.

\section{PROSPECTS FOR ANALYSIS OF ENVIRONMENTALISM BUSINESS AND BEYOND DEMONIZATIONS AND SANCTIFICATIONS}

\begin{abstract}
This paper discusses theoretical and conceptual innovations regarding the environment developed by organizations. From the theoretical framework of institutional theory it explores the different motivations and strategies that can lead companies to take a speech and an attitude of environmental responsibility which is legitimized by society as well as the challenges that lie before the different interpretative frameworks about the phenomenon of the "Corporate Environmentalism." Through the notion of markets as socially constructed institutions, one arrives at a theoretical understanding of environmental innovations-business. In this theoretical model we present four major areas that can be deducted from the environmental innovation developed by firms (1) Capture, (2) Construction of Bridge, (3) Establishment of a New Field and (4) Defense. The phenomena involving the entrepreneurial toward some of these quadrants are understood through the concepts of social capital, political and economic actors in operation when the market, civil society and the sphere of state are in interaction. The analysis points out a number of challenges that present themselves facing the need to build innovation strategies in environmental management more attuned to the recent advances in the discussion and the contemporary social and environmental struggles. Issues that may be subject to further investigation and even competitors comprehensive models of the above in the article.

Key-word: Corporate Environmentalism; Sustainability; Environmental Management; Corporate Social Responsibility.
\end{abstract}

$\overline{\text { Revista de Gestão Social e Ambiental - RGSA, São Paulo, v. 5, n. 2, p. 03-17, mai./ago. } 2011 .}$ 


\section{INTRODUÇÃO}

O campo de conhecimento da gestão empresarial tem sido marcado nos últimos tempos pela introdução de novos conceitos, práticas e tendências. Essas novas tendências, que são assimiladas pelo discurso de lideranças empresariais, passam a fazer parte da agenda de trabalho de gestores preocupados em modernizar as estratégias empresariais e assumem centralidade nas discussões acadêmicas.

Sustentabilidade parece ter adquirido esse status atualmente. Não se trata de um conceito recente, mas tem sido apropriado por diferentes grupos de interesse na sociedade, que o entendem de variadas formas e projetam diferentes expectativas em torno de seus desdobramentos sobre uma gama bastante ampliada de esferas da vida. Desde grupos ambientalistas radicais, passando por organizações não-governamentais, governos e organismos internacionais, e chegando ao mundo empresarial, sustentabilidade tornou-se uma "ideia-força" das mais significativas nos últimos tempos.

$\mathrm{Na}$ esfera da inovação e da gestão empresarial, sustentabilidade é apropriada de diferentes maneiras, com diferentes rebatimentos sobre as estratégias gerenciais. Para os leitores menos familiarizados com a área, essa incorporação pode parecer, no mínimo, estranha: como um mesmo conceito pode servir para dinamizar a indústria e, ao mesmo tempo, proteger o meio ambiente? Para outros leitores, essa convergência seria automática, visto que sem a proteção do meio ambiente não haveria negócios que se sustentassem no longo prazo. Nos campos sociais, não estritamente acadêmicos, os debates e controvérsias também se multiplicam, muitas das vezes reproduzindo concepções e pressupostos dicotômicos sobre as inovações na esfera do ambientalismo empresarial, que dualizam as lutas ambientais entre boas e más intenções, boas e más práticas deliberadas, trazendo mais névoas sobre a compreensão desse fenômeno do que exatamente permitindo a compreensão de sua complexidade. (Teodósio et al, 2005)

Essas divergências e convergências exigem um exame mais detido de como se manifestam, na realidade concreta das experiências organizacionais, as tentativas de inovação de estratégias de negócios envolvendo a sustentabilidade. Neste contexto, as condições externas relativas às políticas públicas seriam indispensáveis para que as empresas possam ter sucesso nesse eixo de inovação (Porter, Vander Linde, 1995). Estas novas perspectivas abririam espaço para a influência de novos stakeholders, preocupados com outros enfoques, além do econômico.

Desta forma, discute-se, por meio deste artigo, a incorporação de variáveis socioambientais pela gestão empresarial, sobretudo por meio da noção de sustentabilidade. Com base no arcabouço teórico da teoria institucional (Flingstein, 1997, Howard-Grenville et al 2008) analisam-se as diferentes motivações e estratégias que podem levar as empresas a assumir um discurso e uma postura legitimada de preocupação com as inovações ambientais em relação a sociedade, bem como os desafios que se apresentam diante dos diferentes quadros interpretativos sobre o fenômeno da difusão da responsabilidade socioambiental empresarial. Quanto à incorporação do conceito pelo campo da gestão empresarial, quatro grandes eixos podem ser delineados. Essa discussão permite se compreender mais profundamente os desafios, perspectivas e armadilhas que se apresentam pela incorporação da variável socioambiental por parte da gestão empresarial.

\section{RESPONSABILIDADE SOCIOAMBIENTAL EMPRESARIAL: UMA LEITURA A PARTIR DA TEORIA DE CAMPOS}

Inspirado na obra de Pierre Bourdieu, Fligstein (2001), define-se os mercados como campos sociais, ou seja, arenas institucionais que estruturam as relações entre seus participantes diretos e indiretos, com base em regras que lhes são comuns e caracterizadas por uma hierarquia colocada frequentemente em questão. A dinâmica organizacional derivaria-se de movimentos dos atores sociais de maior poder, como também da formação e do rompimento das coalisões entre eles 
(Fligstein, 2001b). Os atores mais poderosos não poderiam, simplesmente, impor novas lógicas e normas ao campo, por que, em algum nível, as normas devem ser aceitas pelos outros atores (Beckert, 1999).

Por isso, para entender a dinâmica das organizações, a teoria institucional examina as pressões exógenas para a ação corporativa, aquelas que estão fora de sua fronteira e resultam do relacionamento com o grupo ampliado de atores que estão no campo organizacional. Esta perspectiva amplia o conceito de mercado para além das dimensões de oferta e da demanda. Não só pelos custos, o ambiente externo afetaria a decisão empresarial. Ademais, a questão socioambiental teria um papel decisivo na abertura da "caixa-preta" das empresas e dos mercados. E quando essa "caixa-preta" é aberta, o que se veria em seu interior são pressões sociais, reivindicações, grupos organizados, novas demandas no campo da inovação, tanto quanto interesses privados de acionistas (Abramovay, 2007a).

Neste âmbito, o sucesso empresarial não poderia ser analisado em separado da dinâmica de legitimação social daquilo que perpassa o setor privado (Abramovay, 2007a). A preservação dos ativos empresariais e dos próprios interesses dos acionistas passaria pelas diferentes modalidades por meio das quais as firmas justificariam socialmente o que fazem. A "sinalização mágica" que o sistema de preços oferece aos agentes econômicos seria incapaz de transmitir as informações necessárias para esta gestão.

Para Abramovay (2007a), esta análise traz duas consequências importantes. A primeira, é o convite para se estudar os mercados não como pontos de equilíbrio neutros e impessoais entre agentes independentes entre si, mas sim como estruturas sociais. Os mercados possuem dimensões não-econômicas que não poderiam ser abstraídas de sua dinâmica de operação. $O$ funcionamento dos mercados seria tributário das redes sociais e, neste sentido, seria muito útil abordá-los sob uma perspectiva político-cultural (Fligstein, 2001). Isto leva à segunda consequência: o ceticismo contemporâneo que, entre outros fatores, seria resultado de um certo conformismo e um acanhamento de parcelas importantes dos movimentos sociais e ambientais. Entretanto, tal percepção acerca desse suposto conformismo generalizado, talvez possa não elucidar a verdadeira dinâmica que as inovações ambientais adquirem no campo empresarial. "O mais provável é que as aspirações e as demandas sociais estejam fluindo por canais menos espetaculares que os das grandes manifestações de massa, mas chegando a transformar dimensões cotidianas essenciais da vida social. Faz parte, é bem verdade, daquilo que Max Weber chamou de desencantamento do mundo. Mas abre caminho para uma agenda em que o ambientalismo se mostra mais uma vez, na vanguarda dos movimentos sociais de nosso tempo" (Abramovay, 2007a, p.21).

Um dos aspectos mais relevantes e interessantes na abordagem institucional para se analisar a dinâmica de difusão de inovações ambientais entre as empresas é que ela vai perguntar sempre quais as forças e os interesses sociais vão prevalecer nos processos de mudança organizacional característicos da responsabilidade socioambiental das corporações (Abramovay, 2009). As empresas não poderiam, simplesmente, fabricar realidades artificiais ou escamotear os temas em que estão socialmente pressionadas. Elas enfrentariam desafios que vão além das questões comerciais correntes: os valores em torno dos quais as relações entre firmas se estabilizam e o risco de perda de credibilidade, no caso de ações vistas pela opinião pública como cosméticas ou mentirosas podem ser muito mais prejudiciais do que os gastos realizados para abordar os focos de pressão de forma consistente (Abramovay, 2009, Hoffman, 2000). Sendo assim, cabe se problematizar a emergência do ambientalismo empresarial, compreendendo sua dinâmica histórica, que carrega possibilidades, armadilhas e riscos para a inovação social, e que é ambientalmente necessário por parte das empresas.

\section{AMBIENTALISMO EMPRESARIAL: A INCORPORAÇÃO DO MEIO AMBIENTE PELA AGENDA EMPRESARIAL}

Revista de Gestão Social e Ambiental - RGSA, São Paulo, v. 5, n. 2, p. 03-17, mai./ago. 2011. 
Desde os anos 1960, as empresas estão reavaliando as formas de gerir os problemas ambientais e desenvolvendo novas estratégias para lidar com seus desafios. Nos anos 1970, as corporações viam sua relação com o meio ambiente como uma ameaça externa à lucratividade e às práticas empresariais estabelecidas (Hoffman, 2000). Mas, ao longo das três décadas, com a redefinição do papel do Estado, o fortalecimento das modernas ONGs ambientalistas, as batalhas judiciais e legislativas em torno do meio ambiente e uma crescente atenção da opinião pública com relação ao tema, aconteceu um amplo processo de mudança institucional, que teria dado origem ao chamado ambientalismo empresarial (Hoffman, 2000; Abramovay, 2007a), movimento que fez com que o meio ambiente se tornasse um componente importante na dinâmica das empresas.

Hoffman (2000) concentra sua análise no período correspondente ao desenvolvimento nos Estados Unidos do "movimento ambientalista", iniciado nos anos 1960. "No curso de cerca de três décadas, as normas para as práticas corporativas na área ambiental se alteraram radicalmente" (Hoffman, Ventresca, 2002, p.2). No modelo histórico de Hoffman (2000), a institucionalização do ambientalismo empresarial é desencadeada pela ocorrência de uma série de eventos relacionados ao meio ambiente, tanto no âmbito da sociedade quanto das próprias empresas, cuja percepção é mediada pelo momento histórico e a dinâmica cultural, política e social que os envolve.

A periodização ocorreu nos momentos de ruptura, definidos a partir de eventos, que Hoffman (2000) chama de "críticos e formativos". Um evento pode ser tanto consequência de fenômenos naturais e acidentes ambientais, quanto resultado de mudanças no meio social, político e econômico. Assim, eventos externos dirigem a transição de uma fase para outra, como a publicação do livro "Silent Spring", de Rachel Carlson, em 1962; a descoberta do "buraco" na camada de ozônio ou a imposição de novas regulamentações ambientais mais rigorosas.

Por outro lado, de uma fase para outra teria havido uma expansão no campo organizacional. Por exemplo, a indústria atuava praticamente sozinha durante a primeira fase; enquanto na segunda o governo se tornou um ator importante; na terceira, as mudanças foram dirigidas por associações de indústrias e organizações da sociedade civil, enquanto investidores, companhias de seguro e competidores apareceram como forças importantes na última fase.

Hoffman (2000) identifica quatro momentos diferentes na história do ambientalismo corporativo, caracterizados pelo realinhamento de interesses no campo organizacional: (i) ambientalismo industrial (1960-70), que enfatizava a resolução interna de problemas como um adjunto da área de operações; (ii) ambientalismo regulatório (1970-82), cujo foco era sobre a conformidade com as regulamentações, dada a imposição externa de novas leis ambientais cada vez mais rigorosas; (iii) ambientalismo como responsabilidade social (1982-88), cujo foco era sobre a redução de poluição e minimização de resíduos dirigidos externamente por associações de indústrias e iniciativas voluntárias; e (iv) ambientalismo estratégico (após 1990), que dá ênfase à integração de estratégias ambientais pró-ativas a partir da alta administração. A Figura 1 GonçalvesDias (2009) agrupa as fases da mudança no foco da sustentabilidade no meio empresarial desde os anos 1960. 


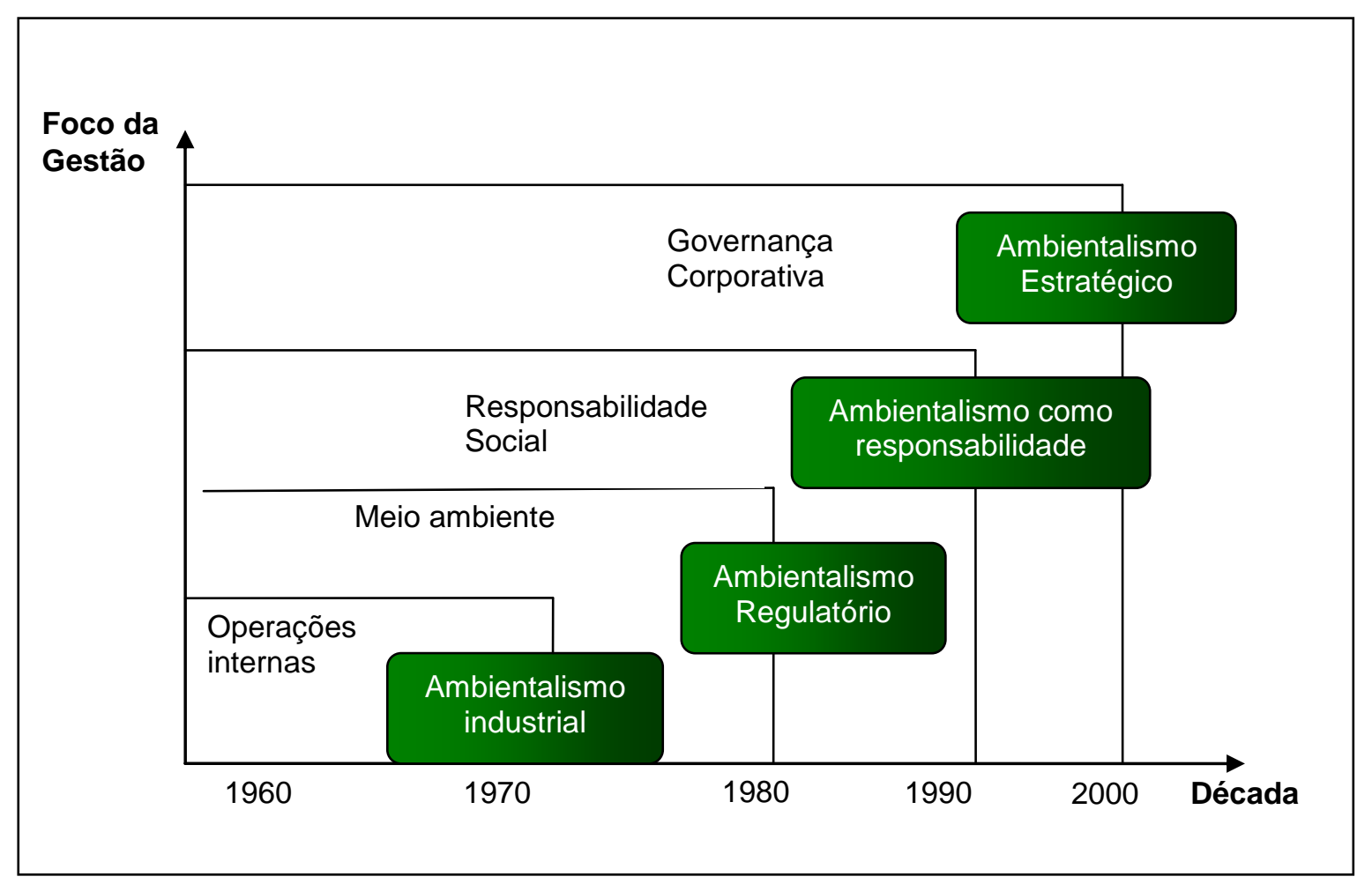

Figura 1: Mudança do foco da sustentabilidade no meio empresarial Fonte: Gonçalves-Dias (2009).

Na década de 1970, o governo teria sido o árbitro primário do desempenho ambiental das empresas. Os gestores viam a relação entre meio ambiente e empresa como uma restrição regulatória imposta pelo governo. Nos debates entre firmas e cidadãos, o poder do ambientalismo estava com o público. Na época, configurou-se a chamada crise ambiental das sociedades industriais modernas (Dunlap, 1991) e nascia um novo movimento ambientalista, considerado “[...]uma contraforça institucional, uma resposta racional e necessária à crise ambiental” (Buttel, 2000, p. 32). Durante as décadas de 1970 e 1980, essas duas forças teriam sido as condutoras predominantes das práticas ambientais corporativas (Cardoso, 2008).

Já na década de 1980, os grupos ambientalistas teriam passado a assumir um papel mais proeminente e direto no direcionamento das estratégias ambientais corporativas. Estes grupos cresceram em poder e influência, em razão do crescimento no número de seus membros e de seus orçamentos, e da especialização e profissionalização de suas atividades. Pesquisa realizada pela Edelman (2003) mostra, por exemplo, que as ONGs ambientalistas na Europa são as marcas mais reconhecidas do que as das empresas privadas. Diante das pressões sociais desses grupos, os gestores desenvolveram práticas ambientais como parte das responsabilidades sociais das empresas (Hoffman, 2000). De outro lado, no período de 1970 a 1985, viu-se o começo de uma integração, embora fraca, entre preocupações ambientais e estratégias de negócios.

Após a segunda metade da década de 1980 teria começado a surgir o ambientalismo como responsabilidade empresarial, uma espécie de "ambientalismo de livre mercado", que trocou a ênfase que era dada nas regulações dos insumos e nas atividades para os resultados. A partir deste período, as empresas começaram a criar departamentos especiais para tratar das questões ambientais como uma forma de atender os requisitos da responsabilidade social. Nestes dois períodos (197080), portanto, as mudanças de práticas ambientais foram uma resposta das empresas tanto para as sanções legais (penalidades civil, administrativas e criminais) quanto sociais (protestos, pressões negativas, redução na reputação e na imagem da empresa). 
Na década de 1990 muitas firmas teriam começado a integrar o meio ambiente nas suas estratégias de negócios, levando ao surgimento de um novo e estratégico paradigma ambiental, que Porter, Kramer (2006) chamaram de ambientalismo estratégico. Nessa década, as ações das firmas na área ambiental teriam se tornado mais pró-ativas e passaram a ser compreendidas como inovações intrínsecas à estratégia competitiva das organizações, vinculando-se à boa performance ambiental, principalmente à melhoria na reputação das empresas.

Desde o começo da década de 1990, portanto, a realidade do ambientalismo no mundo dos negócios teria se tornado mais complexa que a simples conformidade com as leis ou a responsabilidade social. Proteção ambiental e competitividade econômica estavam se tornando entrelaçadas. Diante dessa nova realidade, o que anteriormente era dirigido por pressões que estavam fora do mundo dos negócios direcionava-se por interesses que existiam nos ambientes econômico, político, social e mercadológico das empresas.

Muitas organizações, ao obterem bom desempenho ambiental com a gestão operacional, baixo risco financeiro e perspectivas de sucesso econômico futuro, estariam começando a influenciar as normas de práticas corporativas e estariam transformando o ambientalismo, de externo para algo que está dentro do sistema de mercado e que é central para os objetivos das empresas (Almeida, 2007; Esty, Winston, 2008; Savitz, Weber, 2007). A conclusão é de que o incremento do ambientalismo corporativo é um produto da coevolução de instituições externas e das estruturas e estratégias internas da empresa (Cardoso, 2008).

As empresas, especialmente as grandes corporações mundiais, teriam passado também a orientar o debate, saindo de uma posição reativa para adotar estratégias voluntárias com o intuito de reduzir seus impactos ambientais (Cardoso, 2008). Entretanto, para os teóricos do chamado "moinho de produção", as instituições centrais do capitalismo e da modernização contemporânea - a expansão do mercado, a industrialização, a urbanização, a democracia política ocidental, a inovação científica - continuam levando a uma crescente destruição dos recursos naturais (Abramovay, 2009), Cardoso, 2008; Gould et al., 2004).

A metáfora do "moinho de produção" (treadmill of production) foi criada por Schnaiberg (1980) como resposta para a rápida degradação ambiental que ocorreu nos Estados Unidos após a Segunda Guerra Mundial. Na época, a imagem do moinho descrevia como as forças da competição e da acumulação estavam provocando uma constante expansão do sistema capitalista. Este crescimento econômico exponencial, por sua vez, resultava em impactos ambientais também exponenciais, decorrentes das políticas governamentais e do consumo (Gould et al 2004). Até o final dos anos 1970, a metáfora do "moinho de produção" teria representado o senso comum sobre a relação entre as empresas e o meio ambiente (Abramovay, 2009; Cardoso, 2008).

\section{MOTIVAÇÕES E VETORES DE INOVAÇÃO NO CAMPO DA RESPONSABILIDADE SOCIOAMBIENTAL}

A história do ambientalismo corporativo, desenvolvida por Hoffman (2000), mostra que "[...]mudança organizacional é produto da mudança institucional[...]", denotando como o meio ambiente tornou-se um componente estratégico na vida das empresas. Neste sentido, as instituições não seriam criadas instantaneamente, mas seriam produto da história (North, 1990); ou mesmo poderiam ser entendidas como construções sociais da realidade (Berger, Luckman, 2002). Uma série de novas situações do ambiente institucional teria passado a dirigir as estratégias ambientais das empresas, tais como investidores e acionistas, que estariam interessados em correlações positivas entre o desempenho econômico e ambiental; bancos, que estariam associando performances ambientais ruins ao risco financeiro mais elevado; e associações comerciais, educacionais e religiosas, que passaram a institucionalizar determinadas demandas ambientais em seu modus operandi. 
Pode-se considerar três razões básicas para que as empresas passassem a melhorar sua performance ambiental: primeiro, o regime regulatório internacional estaria mudando em direção às exigências crescentes em relação à proteção ambiental; segundo, o mercado estaria alterando sua compreensão sobre as questões ambientais (tanto em relação aos fatores competitivos quanto aos produtos); e terceiro, o conhecimento ambiental por parte dos atores sociais, estaria mudando, com crescente descoberta e publicidade sobre as causas e consequências dos danos ambientais (Rosen, 2001). Assim, a gestão ambiental empresarial estaria sendo condicionada pela: (1) pressão das regulamentações; (2) busca de melhor reputação; (3) pressão de acionistas, investidores e bancos para que as empresas reduzam o seu risco ambiental; (4) pressão de consumidores e (5) pela própria concorrência.

Nesse cenário, destaca-se a importância das regulamentações e das pressões sociais como propulsoras das inovações ambientais empresariais, e também a importância daquilo que alguns autores chamaram de "eventos críticos" na promoção de mudanças estratégicas nas empresas. Mesmo em estudos mais recentes (Antunes, Santos, Lobo, 2003), Hoffman, 2000), as regulamentações ainda aparecem como um dos fatores centrais na difusão de inovações nas estratégias ambientais empresariais. Não só as estratégias das empresas mais passivas, reativas, ou conformistas, que, em geral, visam apenas a atender à legislação, mas também muitas estratégias aparentemente pró-ativas parecem ser, na verdade, respostas às regulamentações, pois visam antecipar normas e padrões e/ou reduzir o risco de a empresa receber qualquer ação punitiva presente ou futura.

Com isso, é natural que esta intensa regulamentação imponha grande pressão sobre as empresas para que desenvolvam processos de inovação ambiental, muitas vezes de maior relevância do que outros fatores impulsionadores dessas inovações, sobretudo quando se analisa setores com alto potencial poluidor. É neste sentido que, apesar de ressaltarem as oportunidades estratégicas que a gestão ambiental oferece às empresas (como a redução de custos e a diferenciação de produtos), o artigo seminal de Porter e Van der Linde (1995) ressalta que as regulamentações são necessárias, entre outras razões: (1) por criarem pressões que motivam as empresas a inovar; (2) por alertar e educar as empresas acerca da provável ineficiência no uso de recursos e áreas potenciais para melhoramentos tecnológicos; (3) por criar demandas para melhoramentos ambientais, e (4) por evitar que empresas sejam ambientalmente irresponsáveis e com isso deixem também de obter vantagens competitivas em função disso.

$\mathrm{Na}$ figura 2, sintetizam-se os principais fatores que influenciam o comportamento ambiental das empresas, atuando assim como forças propulsoras da adoção de estratégias ambientais. 


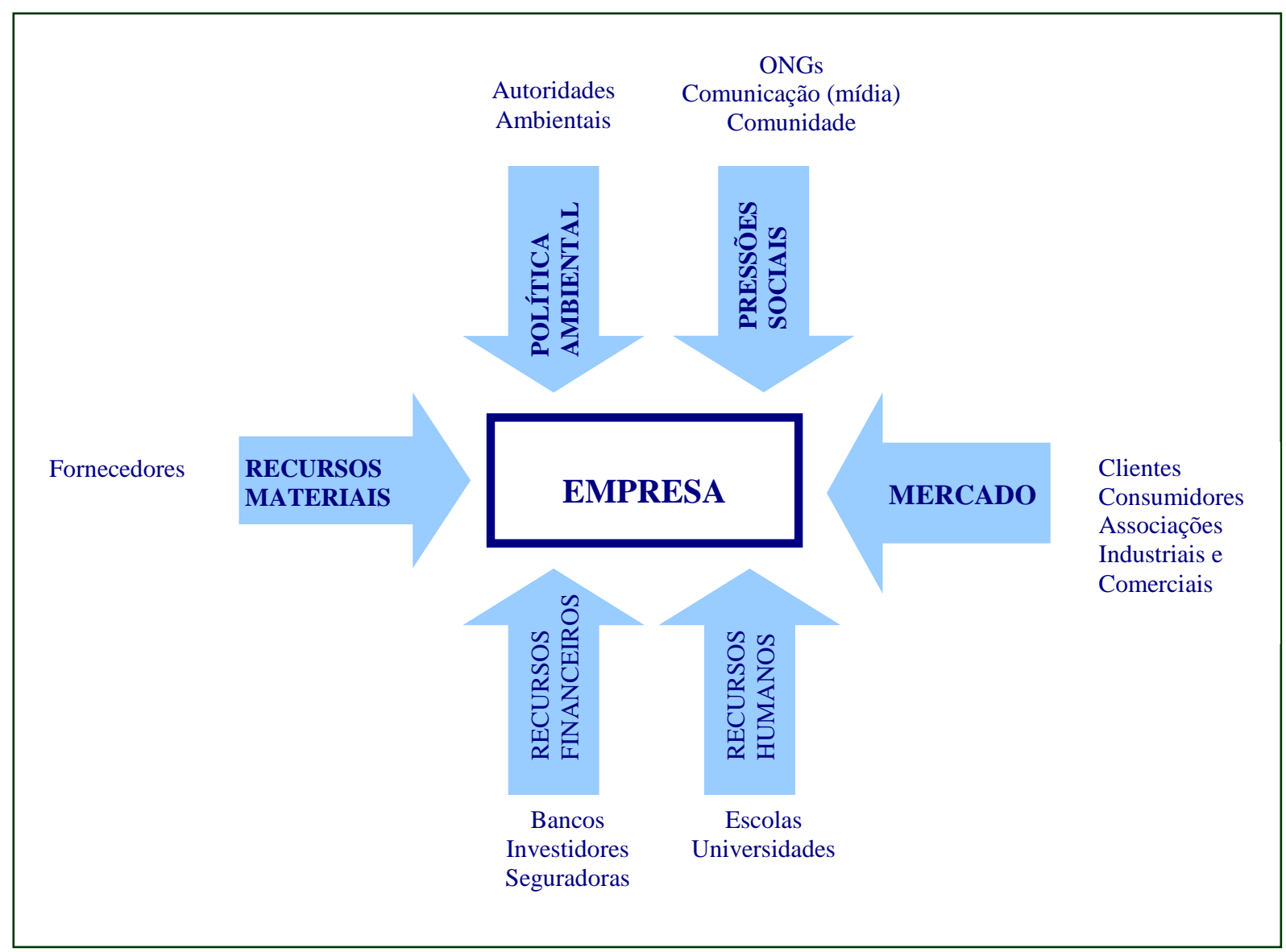

Figura 2: Pressões para a adoção de estratégias ambientais nas empresas Fonte: Antunes e Lobo (2003, p. 34).

Mas, quais seriam os fatores mais importantes na difusão de inovações ambientais entre as empresas? Para Hoffman (2000), os governos e ativistas sociais têm sido historicamente os mais proeminentes elementos a dirigirem as práticas ambientais corporativas. Entretanto, tem havido uma evolução nas estratégias das empresas em direção à incorporação de parâmetros ambientais em suas estratégias competitivas. As práticas ambientais corporativas, neste contexto, têm se tornado menos uma questão ambiental e mais uma questão de inovação em diferentes dimensões das estratégias competitivas e áreas das organizações: marketing, finanças, relações humanas, eficiência operacional e desenvolvimento de produtos (Souza, 2002).

$\mathrm{O}$ atendimento das exigências relativas às três dimensões da sustentabilidade - ambiental, social e econômica -, pressupõe mudanças na estrutura de governança empresarial, nas alterações do processo decisório, na estrutura organizacional e nos padrões de inovação tecnológica adotados pelas empresas (Daroit, Nascimento, 2004; Melo Neto, Brennand, 2004).

O conflito na relação entre empresas, governos e público ainda persiste, mas, ao mesmo tempo, teriam sido desenvolvidas uma maior diversidade de abordagens cooperativas entre empresas e governos, entre empresas e organizações não-governamentais (ONGs) e mesmo entre as próprias firmas com o objetivo de melhorar o desempenho ambiental do setor privado, sendo muitas delas alternativas baseadas no mercado (Abramovay, 2009); Hommel, 2004; Cashore et al, 2004; Conroy, 2007).

Naquele período seria cada vez mais comum as empresas desenvolverem mecanismos de autorregulação e criarem políticas socioambientais que iriam além das exigências legais (CARDOSO, 2008). Uma crescente literatura sobre políticas de parceria aponta que surgiu uma nova "era da colaboração" nos anos 1990, caracterizada por parcerias público-privadas, 
colaborações interorganizacionais e alianças empresas-organizações não-governamentais (Murphy, 1998; Cardoso, 2008). As empresas contemporâneas praticariam o que Hommel (2004) denominava de gestão antecipada da contestabilidade. O cerne desta explicação está na ideia de que a presença da empresa no mercado depende de uma legitimidade, que é permanentemente contestada por um conjunto variado de atores. A "gestão antecipada da contestabilidade" não seria um evento em que a empresa responde apenas em casos extremos, mas, ao contrário, faria parte de sua atividade cotidiana. Nas situações em que esse preceito foi subestimado - como no caso dos organismos geneticamente modificados, na Europa (Abramovay, 2007) - as consequências econômicas desastrosas manifestaram-se de forma clara. Abramovay (2009) destaca que nesta abordagem a responsabilidade social empresarial aparece como componente organicamente integrado ao próprio funcionamento dos mercados e não como manifestação de boa consciência ou da tentativa de atenuar os efeitos nefastos das atividades econômicas.

Esse processo, chamado de "greening of the business", teria emergido após a institucionalização do próprio conceito do desenvolvimento sustentável ao longo dos anos 1990 (Nobre, 2002, Veiga, 2005). Para alguns autores (Hart, 1998; Porter, Van Der Linde, 1995; Porter, Kramer, 2006; Elkington, 1994), os temas ambientais, em particular, têm influenciado os modelos de administração empresarial, gerando oportunidades competitivas para um número crescente de empresas desenvolverem processos de inovação tecnológica. Outros (Hoffman, 2000; Hoffman, Ventresca, 2002; Pulver, 2007) apontam ainda que novas instituições, construídas a partir da crise ambiental, estariam alterando a forma de organização das empresas e da economia de mercado em geral.

Por outro lado, as organizações ambientalistas e outros movimentos sociais também vêm optando por posturas mais cooperativas com o setor privado e com o Estado. O movimento ambientalista, em especial, teria se profissionalizado e a insurgência dos anos 1960 e 1970 teria dado lugar a comportamentos mais "flexíveis". E, assim, passados mais de 30 anos, depois de certo refluxo das lutas ambientais nos anos 1980, a crise ambiental teria voltado às manchetes com destaque renovado, em decorrência das mudanças climáticas (Arts, 2002; Cardoso, 2008). A concepção de como as empresas se relacionam com o meio ambiente também teria mudado. Por um lado, “[...]as empresas estão no meio ambiente, sob a forma de emissões, destruição da biodiversidade, poluição e comprometimento freqüente do patrimônio social e natural em que intervêm. Por outro, o meio ambiente (isto é, os ecossistemas dos quais as sociedades humanas são parte integrante e indissolúvel) também está nas empresas" (Abramovay, 2008, p. 13).

A presença das empresas na vida social seria cada vez mais importante e nela se encontraria um dos caminhos de mudança e inovação em direção à sustentabilidade no mundo contemporâneo. Para isso, é fundamental se reconhecer a dependência mútua entre as empresas e sociedade. Nessa dinâmica, se as empresas ignoram suas responsabilidades socioambientais, muitos custos implícitos podem se tornar explícitos. Assim, se a organização se descuida de suas práticas ambientais, as agências governamentais podem impor regulamentações mais rigorosas. Similarmente, se a empresa continua a agir de maneira irresponsável, outros stakeholders podem duvidar de que a firma honrará com os compromissos para consigo, por exemplo, os bancos (Toms, 2001). Desta forma, firmas que apresentam alto nível de responsabilidade socioambiental teriam menores custos implícitos do que aquelas que ignoram a responsabilidade social. Assim, a redução do risco seria um importante condutor da inovação das estratégias socioambientais das organizações (Lau; Ragothaman, 1997).

Obedecer à premissa de responsabilidade social empresarial estratégica, conforme Porter, Kramer (2006), em que as firmas não precisariam esperar pelo aparecimento de novas regulamentações oficiais para garantir seu desempenho ambiental, diz pouco sobre a profundidade e o alcance do que faz a empresa (Abramovay, 2009). O importante seria compreender sob qual dinâmica sociopolítica as inovações ambientais nas empresas podem se manifestar. 


\section{INVESTIMENTO SOCIOAMBIENTAL EMPRESARIAL: DIFUSÃO E LEGITIMAÇÃO}

As ações socioambientais das empresas estariam enraizadas em um campo no qual os atores têm poder assimétrico para estabelecer normas gerais (Howard-Grenville et al 2008). São vários os capitais que permitem a cada um dos participantes num campo ocupar suas posições e lutar para melhorá-las (econômico, cultural, social e político, entre outros). A estrutura de um campo não resulta, de maneira imprevisível, da interação entre seus protagonistas, mas dos capitais que foram e são capazes de reunir e mobilizar. A mudança e a profundidade da mudança num campo social dependeriam fortemente destes vários capitais, dos quais o financeiro se constituiria em apenas um deles (Howard-Grenville et al 2008).

O sucesso na adoção de novas práticas, consideradas pelos atores sociais como benéficas, depende da capacidade de as empresas reunirem capitais diversificados para enfrentarem seus novos desafios. Neste contexto, não bastaria poder econômico: seriam necessários conhecimentos técnicos, contatos, tradição na área, capacidade persuasiva, liderança, inserção em redes variadas de atores e capacidade de interagir com estas redes. Em outras palavras, a inserção das diferentes organizações nos campos sociais, que são os mercados, passaria por sua capacidade de reunir capitais cuja importância é heterogênea na maneira como o próprio campo se estrutura.

Qual seria, então, o poder transformador das inovações na esfera da responsabilidade socioambiental? Para a teoria dos campos, isso vai depender dos capitais (quer sejam social, cultural ou econômico) que os diferentes atores em conflito serão capazes de mobilizar e colocar em ação (Abramovay, 2009, Howrd-Grenville et al 2008). Embora os programas de produção mais limpa ou qualidade ambiental privilegiem a dimensão econômica, eles representariam um movimento que aponta para a existência de pressões ambientais e sociais sobre as organizações (Dairot, Nascimento, 2004). Estas pressões se refletem em novas demandas, cujo atendimento depende da geração de inovações. As inovações deixariam de ser puramente orientadas para resultados econômicos e passariam a incorporar os limites impostos pela sociedade e pelo meio ambiente, considerando também as futuras gerações. Isto faz com que a geração de inovações torne-se mais complexa, pela existência de um maior número de stakeholders envolvidos, e mais ambígua, pois os stakeholders podem apresentar interesses conflitantes (Hall, Vredenburg, 2003). Sob a ótica econômica, os interesses que prevalecem seriam aqueles que resultam em maior rentabilidade do negócio, já com o desenvolvimento sustentável, os interesses voltados para o bem-estar social e preservação dos recursos naturais também exerceriam peso nas escolhas tecnológicas e decisões estratégicas da organização.

O caso da certificação, por exemplo, seria emblemático. Foi durante os últimos quinze anos que prosperaram iniciativas internacionais voltadas ao rastreamento e à certificação socioambiental. Produtos florestais, indústrias têxteis, de roupas e acessórios, setor naval e de pesca, construção civil, turismo, indústria química, mineração, transportes e diferentes segmentos da agricultura respondem, ao menos formalmente, a protocolos que envolvem o rastreamento de suas atividades e a certificação dos produtos. Os efeitos práticos da certificação são, evidentemente, desiguais. Em muitos casos - como no uso do carvão vegetal oriundo de matas nativas para a siderurgia, por exemplo (Abramovay, 2009) - o rastreamento permitiu avanços, mas não conseguiu impedir os piores procedimentos. Além disso, a certificação envolve custos que podem limitar severamente o acesso aos mercados dos produtores com menor poder econômico.

Howard-Greenville et al (2008) procuram sistematizar estas possibilidades, estudando quatro modalidades de inovação socioambiental pela gestão empresarial (figura 3 ).

Revista de Gestão Social e Ambiental - RGSA, São Paulo, v. 5, n. 2, p. 03-17, mai./ago. 2011. 


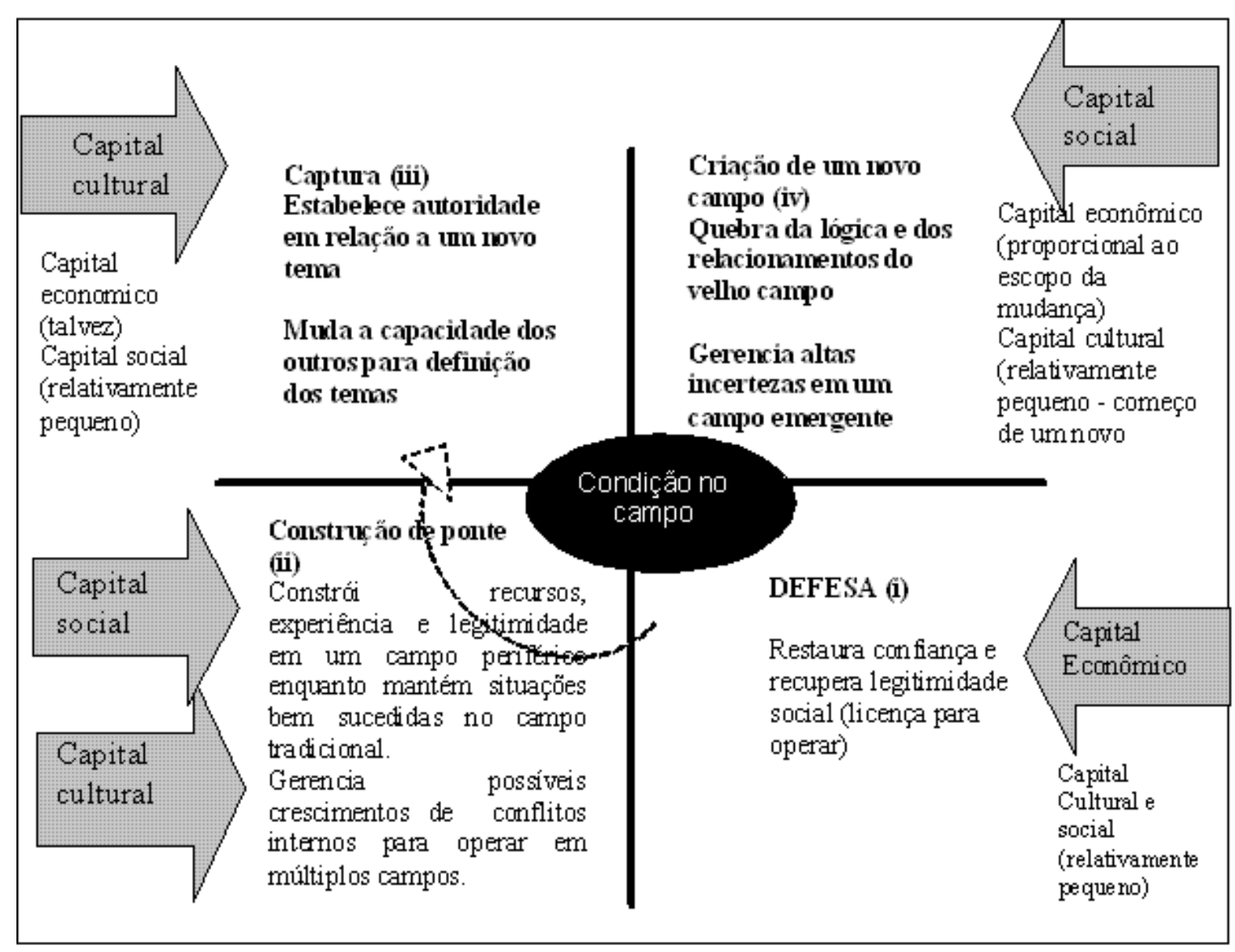

Figura 3: Modalidades de inovação empresarial frente a questões socioambientais Fonte: Elaborado pelos autores a partir de Howard-Grenville et al (2008).

A primeira delas refere-se à defesa, por parte das empresas, de um campo em crise e no qual se procura restaurar a confiança provocada por episódios especialmente marcantes, como no caso dos vazamentos de petróleo em reservas ambientais, sem mudanças significativas no padrão de operação das organizações. Neste caso, o peso do capital econômico é maior que o do capital social ou cultural. A segunda modalidade de intervenção é definida como construção de pontes: a criação de instâncias para discutir temas socioambientais com ONGs e movimentos sociais seriam um excelente exemplo disso. A terceira modalidade de intervenção envolve a captura, por parte de uma empresa, ou grupo de empresas, de questões socioambientais, sem alterar, porém, as relações entre seus membros, ou as relações de poder existentes no setor. Seria necessário reunir capital cultural capaz de persuadir formadores de opinião de que estas mudanças são reais e significativas, ainda que não alterem as forças que dominam o mercado em questão. A quarta modalidade estaria no esforço de criar um novo campo social e, em torno dele, organizar o mercado: alguns dos exemplos citados por McDonough e Braungart (2002) sobre sua determinação em elaborar produtos não apenas menos nocivos que os habituais, mas capazes de regenerar os sistemas ecológicos em que interferem, enquadrariam-se certamente nesta categoria.

A sustentabilidade, antes uma categoria restrita aos padrões ambientais, teria se tornado a nova palavra de ordem no mundo dos negócios (Melo Neto, Brennand, 2004). Entretanto, para uma empresa tornar-se sustentável, deve ir além do produzir e do vender, para agir como agente promotor do desenvolvimento sustentável em todas as suas dimensões. Adotar práticas de gestão ambiental (processos limpos de fabricação, monitoramento das emissões atmosféricas, reutilização 
de insumos, entre outros) não é suficiente para assegurar sustentabilidade a um negócio e garantir que a empresa atende o paradigma da sustentabilidade.

Quando no conceito de desenvolvimento sustentável afirma-se que é preciso atender as necessidades da sociedade atual sem comprometer a sociedade futura, deve-se entender que ele não representa um rompimento com o capitalismo, mas acrescenta uma dimensão ética ao modelo de crescimento econômico (Leis, 1999).

Esta definição estaria focada somente no meio ambiente, entretanto é importante colocar atenção no envolvimento das empresas em um amplo sistema social, que compreende o sistema de produção industrial, visto que a própria noção de sustentabilidade, na formulação original de Ignacy Sachs (2007), compreende as dimensões ambiental, econômica, social (equidade), política (democracia participativa) e territorial (região e seu significado e apropriação culturalmente construídos pelos povos). Essa formulação implica se compreender que a legitimação do discurso do ambientalismo empresarial não consegue se sustentar apenas pelo apelo em relação ao meio ambiente per si, visto que diferentes atores sociais remetem ao campo ambiental variadas concepções, projetos e demandas, nos quais se entrecortam aspectos sociais, políticos, culturais e econômicos na construção da noção de sustentabilidade.

\section{6 À GUISA DE CONCLUSÃO: AVANÇOS, DESAFIOS E PERSPECTIVA DO AMBIENTALISMO EMPRESARIAL}

Cabe destacar alguns pontos importantes evidenciados ao longo deste artigo. Primeiro, procurou-se demostrar uma evolução na natureza das ações ambientais empresariais. Esta evolução, apesar de aparentar ser generalizada, não é uniforme, variando de acordo com o contexto institucional, e, por desdobramento, com o setor econômico e de empresa para empresa. $\mathrm{O}$ elemento central na análise das inovações ambientais das empresas seria a dinâmica de cada campo organizacional (instituições, concorrentes, fornecedores e mercados) e o tipo de resposta que cada empresa tem dado às questões ambientais.

A noção de sustentabilidade desperta debates intensos, mobilizando "corações e mentes" de movimentos ambientais, comunidades, governos e também dos gestores de empresas. A transição de modelos gerenciais tradicionais para estratégias sustentáveis de negócios se faz por caminhos tortuosos. Os desafios com os quais se deparam as empresas são muitos, até mesmo porque temas como degradação ambiental planetária, fome, desigualdade social e conflitos armados nunca foram incorporados à agenda das organizações privadas ou ocupavam lugar secundário nas estratégias corporativas antes das transformações sociais e ambientais das últimas décadas.

As escolhas empresariais na esfera da inovação não envolvem apenas seleção de tecnologias, preços e procedimentos produtivos, mas também a maneira como vão se relacionar com as dimensões socioambientais do que fazem, ou, em outras palavras, à qualidade de sua inserção social e ambiental (Abramovay, 2008). No entanto, isso exige, com frequência, transformações tanto na visão que a empresa tem de seus recursos, quanto, sobretudo, de suas relações com os stakeholders. Estes stakeholders compreendem desde comunidades locais e grupos preocupados com a biodiversidade até investidores temerosos dos riscos que a destruição dos ecossistemas poderia trazer à própria legitimidade (licença para operar na realidade social) da empresa. Neste sentido, percebe-se que a argumentação de Abramovay (2008) embute preceitos da corrente contratualista, pois considera que a empresa opera no mercado, que, por sua vez, é entendido, fundamentalmente, como construção social, mas, também agrega preceitos da visão estratégica na gestão da responsabilidade socioambiental, afinal, “[...]socioambiental não é um setor à parte, como uma equipe de bombeiros convocada quando a temperatura sobe, mas sim um componente estratégico que deve ser incorporado ao negócio e do qual depende a integridade de qualquer organização contemporânea" (Abramovay, 2008, p. 13). Essa convergência de dimensões compreensivas pode resultar em importantes avanços na análise do fenômeno do ambientalismo 
empresarial, permitindo que se ultrapasse concepções dicotômicas e/ou maniqueístas, infelizmente ainda muito presentes tanto na produção científica sobre inovações ambientais das empresas, quanto no próprio senso comum construído pelos atores nas sociedades contemporâneas.

No contexto atual em que duas crises se encontram - a financeira e a ambiental (Abramovay, 2009), amplia-se a importância da discussão do dilema retratado ao longo deste artigo. Há um extraordinário potencial para construir novos modos de relações entre os indivíduos e o mundo natural. O esforço empresarial de se voltar a esses temas acena para interessantes possibilidades de avanço. Para os céticos, esse esforço se perderá com o tempo, tornando-se mais uma das tendências passageiras da administração contemporânea. Para aqueles que olham o futuro com otimismo, a gestão organizacional se tornará mais transparente, responsável e frutífera para todos os stakeholders envolvidos no negócio. Independentemente dos prognósticos, fica evidente a necessidade de se operar as análises sobre inovações ambientais no campo empresarial sob um esquema teórico-compreensivo mais complexo, capaz de lidar igualmente com as possibilidades, armadilhas e riscos que o ambientalismo empresarial apresenta à sociedade.

Espera-se que, a partir da estrutura analítico-conceitual que orientou as discussões desse artigo, possam ser realizadas novas investigações que avancem no entendimento do fenômeno do ambientalismo empresarial, quer seja dentro dos eixos teórico-conceituais adotados ou se contrapondo a eles. O importante é não se perder de vista a centralidade de se avançar a agenda de pesquisa e de produção de conhecimento tanto no campo acadêmico quanto no âmbito dos estudos realizados por organizações da sociedade civil, do governo e empresas, de forma a se problematizar o envolvimento dos atores de mercado com as questões ambientais para além de simplismos e dicotomias, que pouco explicam e mais servem para tornar mais nublado o horizonte das preocupações e também das inovações ambientais que rondam as sociedades contemporâneas.

\section{REFERÊNCIAS}

Abramovay, R. (outubro 2007a) Ambientalismo empresarial. Le Monde Diplomatique Brasil. 21.

Abramovay, R. (edição de 30 de novembro 2007b) Oposições à empresa verde. Valor Econômico.

Abramovay, R. (2007c) "Bem vindo ao mundo da controvérsia". In: José Eli da Veiga. (Org.). Transgênicos sementes da discórdia. São Paulo: SENACp. 129-168.

Abramovay, R. (edição de 19 de setembro 2008) A dimensão estratégica da responsabilidade socioambiental. Valor Econômico, p. A 13.

Abramovay, R. (2009) Anticapitalismo e inserção social dos mercados: uma crítica sociológica ao pensamento de André Gorz. In: Tempo Social, Revista de Sociologia da USP, 21(1), São Paulo, (no prelo).

Abramovay, R. (2009) Responsabilidade socioambiental: as empresas no meio ambiente, o meio ambiente nas empresas. In Veiga, J.E. (org.) Economia socioambiental. São Paulo: Editora SENAC (no prelo)

Antunes, P., Santos, R. Lobo, G. (2003) Estratégias Ambientais das Empresas do Sector Electro. [Relatório de Pesquisa sobre o Setor Eletro, 4]. Lisboa: Centro de Economia Ecológica e Gestão do Meio Ambiente, Universidade Nova de Lisboa. 
Buttel, F.H. 2000. Classical Theory and Contemporary Environmental Sociology: some reflections on the antecedents and prospects for reflexive modernization theories in the study of environment and society. In: Spaargaren, G.; Mol, A.P.J. \& Buttel, F.H. (eds); Environment and Global Modernity. London, UK: SAGE Studies in International Sociology, pp. 17-39.

Gonçalves-Dias, S. L. F. (2009) Catadores: uma perspectiva de sua inserção no campo da indústria de reciclagem, 2009. 298 f. Tese (Doutorado) - Programa de Pós Graduação em Ciência Ambiental, Universidade de São Paulo, SP, Brasil.

Hall, J., Vrendenburg, H. (2003) The challenges of innovating for sustainable development. MIT Sloan Management Review, 61-68, fall.

Hoffman, A. J. (2000) Integrating environmental and social issues into corporate practice. Environment. Abringdon, Carfax Publishing. Jun.

Hoffman, A. J.; Ventresca, M. J. (2002) Organizations, Policy and the Natural Environment: institutional and strategic perspectives. Stanford, California : Stanford University Press, 489.

Hommel, T. (2004) Stratégies des firmes industrielees et contestation sociale. Paris: Cemagref/Cirad/Ifremer/Inra Éditions.

Howard-Greenville, J., Hoffman, A., Bhattacharya C. B. (2008) Who Can Act On Sustainability Issues? Corporate Capital And The Configuration Of Organizational Fields. In: Sharma, S., Starik, M., Husted, B. (ed) Organizations and the Sustainability Mosaic. Northampton: Edward Elgar.

Lau, R. S. M., Ragothaman, S. (dec.1997) Strategic issues of environmental management. South Dakota Business Review. Vermillion, 56.

Leis, H. R. (1999) A modernidade insustentável. Petrópolis: Editora Vozes, 261.

Porter, M. E.; Kramer, M. R. (dec 2006) Strategy and Society - the link between competitive advantage and corporate social responsibility. Harvard Business Review. pp. 1-14.

Porter, M. E., Van Der Linde, C. (sep-oct 1995) Green and competitive. Harvard Business Review. pp. 120-134.

Rosen, C. M. (Sep.2001) Environmental strategy and competitive advantage: an introduction. California Management Review. Berkeley, Haas School of Business, 43.

Sachs, I. (2007) Rumo à ecossocioeconomia - teoria e prática do desenvolvimento. São Paulo. Cortez Editores.

Souza, R. S. (2002) Estratégias ambientais empresariais: evolução, fatores condicionantes e tipologias. Encontro Nacional de Pós Graduação em Administração. In: Anais... Florianóplis.

Teodósio, A. S. S., Barbieri, J. C., Csilag, J. M. (nov.2005) Montando o mosaico da sustentabilidade organizacional. In: 4th International Meeting of the Iberoamerican Academy of Management. In: Proceedings.... Lisboa/Portugal: IAM, 8-11/nov, pp. 1-15. 
Toms, S. (Jan. 2001) Eco-logical. Financial management. London, FMAI.

Data do recebimento do artigo: 25/03/2011

Data do aceite de publicação: 20/08/2011

Revista de Gestão Social e Ambiental - RGSA, São Paulo, v. 5, n. 2, p. 03-17, mai./ago. 2011. 